insert the form of Certificate which is in use by Dr. Sykes at St. Pancras.

Certificate of Medical Officer of Hiealtr.

Having been furnished with evidence that the assessment to Inhabited House Duly of the house described below will be wholly or partly discharged by the Commissioners acting in the execution of the Acts relating to Inhabited House Duties, provided that a Certificate of the Medical Officer of Health be produced, and having been requested to furnish the said Certificate, I hereby certify that I have examined the house described below, and am of opinion that the house is so constructed as to afford suitable accommodation for each of the persons inhabiting it, and that due provision is made for their sanitary requirements, these words being interpreted to mean that the house is so constructed :-

I. - That each of the persons inhabiting it is provided with at least four hundred cubic feet of air space.

2.-That each of the living or sleeping rooms is at least eight feet in height, and at least sixty-four square feet in area.

3. - That there is at least one draw-tap and sink, with a sufficient supply of water thereto, for every tweive occupants or less, on each floor.

4. - That there is at least one water closet, properly supplied with water, for every twelve occupants or less, on each floor.

5.-That the drainage of the premises is in accordance with the Regulations recognised by this Authority.

6. - That accommodation for clothes-washing is provided, sufficient for the number of persons inhabiting the house.

Name and Situation of House.................................

Name of O......................................................

Date.......................................

\section{Medical Officer of Health for the}

District of St. Pancras.

In addition to the above, questions of light and air are decided on the merits of each individual case, and conditions which can be rectified under the Public Health Act are omitted.

\section{ENTERIC FEVER IN THE COUNTY OF DURHAM.* \\ By T. Eustace Hill, M.B., B.Sc., County Medical Officer} of Health for Durham.

THE past year was remarkable for the extreme prevalence of this disease in very many of the sanitary districts of the county. The number of deaths during the year was 447 , equal to a deathrate of 0.60 per 1,000 , against 131 deaths in 1892 , with a rate of 0.19 per 1,000 . In England and Wales, the death-rate from enteric fever, though higher than for several years past, was only $0.2 \mathrm{I}$ per 1,000 , or a little more than a third the rate for this county. The total number of cases notified in the county was 2,674 , giving a case mortality of 16.7 per cent., and a sickness rate of 0.60 per 1,000 of the population. The death rate per $\mathrm{I}, 000$ population from enteric fever was in Shildon, 3.9; Bishop Auckland, $\mathbf{r}^{\circ} 6$; and Houghton (Northern Division), x.6; while it exceeded I.O per 1,000 in Houghton-le-Spring, Southwick, and in the Easington rural district. The only sanitary district in which no death from enteric fever was registered during 1893 was Stanley (urban).

\footnotetext{
* From Dr. E. Hill's Annual Report, 1893.
}

There can be no doubt that the chief predisposing cause of the exceptional prevalence of the disease was the seasonal conditions of last year which were extremely favourable for its development, the great heat promoting rapid decomposition, while the extremely dry weather seriously affected the water supplies in many districts, and also prevented the proper flushing of sewers and drains. Various explanations of the actual cause of the disease are given by the district medical officers of health (including in individual cases polluted water and milk, the opening out of some old sewers, leakage from privy-middens). . . In the northern division of the Houghton rural district, enteric fever outbreaks at Penshaw and Warden Law were undoubtedly the result of the importation of infected town manure from Sunderland. . .. . But in many villages where enteric fever was very prevalent the sanitary circumstances were very fair, and no suspicion could with certainty be attached to either the milk, or water supply, or drainage. I investigated several outbreaks of this description and was forced to the conclusion that the methods of excrement disposal and removal employed were the most probable cause of the disease. Whatever the cause of the first case of enteric fever in such places-whether by introduction from another district, or by an ordinarily innocuous organism assuming under favourable conditions the pathogenic properties of the typhoid bacillus, or by any other means-it is highly probable that the excreta of such patient are at first thrown into the ashpit without disinfection. The contents of an ordinary midden privy are favourable for the existence and development of the typhoid bacillus, and during the time that the middens are being emptied the germs of the disease are most likely to be disseminated.

In most of the houses of the working classes in this county the midden-privies are situated within a few yards of the back doors and pantry windows, and their contents are, at any rate in the colliery villages, almost invariably removed during the day when both the back door and the pantry window will, especially in hot weather, often be open, and when food will be lying about. The dust created by the emptying of a large midden either directly into the scavenger's cart, or first on to the ground and then into the cart, is very great, and if there is any wind much of this dust, carrying infected matter (if infected excreta have been thrown into the ashpit), is carried into the nearest houses, and must settle on the furniture, food, etc. Frequently also in the colliery villages the scavenger's open carts carrying the contents of several middens have to pass along the street within a few feet of the doors of the houses, and the light dust from these is often blown into the houses.

According to experiments by Uffelmann (Brit. Med. Fournal, May 5th, r894) the typhoid bacilli retain their power of development in house and 
street sweepings for at least 30 days in a dry air, and for a longer time in a moister atmosphere (such as a midden), and his experiments also establish that the bacilli are carried into the air with dust from floors, streets, and clothing, and are thus enabled to infect milk and other food.

Dr. Mitchell, M.O.H. for Hepburn, County of Durham, gives as his opinion that while the pre. disposing causes were the extreme heat and prolonged drought, the distribution of the disease, especially during its early prevalence, pointed to the actual cause being in some way dependent on the ashpit-privies; for though there are many more ash closets in the town than midden-privies, there were more than three times as many cases in houses dependent on the latter form of privy accommodation.

\section{ENTERIC FEVER AT ST. HELENS. *}

By R. NICHOLI, M.R.C.S., late M.O.H. for St. Helens. I HAVE been able to calculate the number of cases of sickness from typhoid fever per $I_{3}, 000$ of the population in the large towns of England during I 893 , and this table is printed below :-

Rate per I,000 of Cases of Sickness from Typhoid

$$
\text { Fever, } 1893 \text {. }
$$

London ........... $\quad 85$ Manchester $\quad \ldots \ldots . \times 2$

Croydon............ $3.3 \quad$ Oldham ........... ${ }^{2} \mathrm{r}$

West Ham ........ I ${ }^{3} 5$ Burnley ........... I'3

Norwich ........... $30 \quad$ Blackburn ......... $: 2$

Plymouth ........ '64 Preston ........... I'7

Bristol............. '50 Huddersfield ...... ${ }^{5} 8$

Wolverhampton ... I.8 Halifax ........... 73

Birmingham ...... I' 1 Bradford............ ${ }^{\circ} 6$

Leicester............ $22^{\circ} \circ \quad$ Sheffield ........... $\mathbf{r}^{\prime} 3$

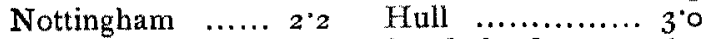

Derby ............. I 109 Sunderland......... 6.00

Birkenhead ......... 2 ${ }^{\cdot} \mathbf{I}$ Newcastle-on-Tyne $7 \mathbf{1}$

Liverpool ........ $22^{\prime} 7 \quad$ Cardiff $\ldots \ldots \ldots \ldots .72$

Bolton.............. I'3 Swansea ........... I'I

Salford ........... $2^{\prime} 7$ St. Helens …..... $4^{\prime} z$

From the above it will be seen that only one town had a larger sickness rate from typhoid fever amongst the great towns of England than St. Helens. Amongst the smaller towns there were several which had as great or greater rates than St. Helens.

The main factors in producing this disease at St. Helens have been dwelt upon in former reports, and during the last year additional evidence has accumulated that these factors do play the important part that has been ascribed to them. Of the cases of typhold fever $x$ ' $x$ occurred per 100 houses on the w.c. system; 3.4 occurred per roo houses on the privy system; and $I^{\circ} 7$ occurred per roo houses on the tub and pail system. Therefore, typhoid fever occured twice as frequently in houses on the privy system as in houses on the tub and pail system, and three times as frequently as in houses on the w,c. system. This is in complete accordance with the result obtained in $x 89 \mathrm{r}$.

\footnotetext{
* From Mr. Nicholl's Annual Report for 1893 .
}

\section{PREVENTIVE MEASURES IN SMALL POX*}

By A. Wellesley HaRRts, M.R.C.S., etc., M.O.H. for Southampton.

From January ist to September $\mathrm{I}_{5} \mathrm{th}, \mathrm{I} 893$, I 53 cases of small-pox occurred in Southampton, being a continuance of the outbreak which began December $25^{\mathrm{tb}}, \mathrm{r} 892$. The difficulty experienced in controlling this outbreak was in a great measure due to the fact that the majority of cases existed in the courts and alleys. From the description of these places given in the recent special report, the dangers with which we were beset at the time of the outbreak will be readily understood. The whole of this number, with one exception, were isolated in hospital by the Health Authority, the one exception being due to the condition of the patient precluding his safe removal. He died at home $a_{2}$ few hours after notification of the case.

Our system of procedure in cases where opposition was offered to removal was to place two inspectors outside the house to warn and prevent persons from the outside entering, and to caution persons leaving the house that legal proceedings would be taken against them for exposing infected articles, namely, their clothing, to the common danger of the public, they coming from an infected house, under the provisions of the Public Health Amendment Act. This had the effect of soon bringing a request from those having the custody of the sick, or from the patients themselves, to be admitted to hospital.

Every possible care was taken to check the spread of the disease. The medical officer of health, without waiting for the result of his notification to the vaccination officer, visited every house in which cases occurred, and in the immediate neighbourhood, offering gratuitous vaccination. Notices were also issued that persons might be revaccinated at his office every evening at seven o'clock. By this course between three and four hundred vaccinations were carried out. Several persons who had been exposed to infection refused revaccination, many of them contracting the disease at the termination of the usual period of incubation.

Case 43 is an excellent example, Two constables had occasion to visit a house in which a boy was suffering from small-pox (discovered after their visit). Finding they had made this visit, 1 immediately inquired at head-quarters who these men were, and informed the inspector that they should be immediately revaccinated, and that I would perform the operation if they would come to my house. When they came I could persuade only one to submit to the proposal, with the result that he escaped, while the other, who refused, was admitted to hospital a fortnight later with severe confluent small-pox, from which he nearly lost his life.

* From Mr. Harris' Annual Report for 1893. 